\title{
ANALISA PERHITUNGAN EFESIENSI DAN RUGI-RUGI PADA TRANSFORMATOR DISTRIBUSI KILANG FRAKSINASI PT. PERTA-SAMTAN GAS
}

\author{
Surya Darma $^{[1]}$ / Hazalin Alferon ${ }^{[2]}$ \\ suryadarma.st.mt@gmail.com \\ hazalin7@gmail.com \\ Dosen Tetap Prodi Teknik Elektro Fakultas Teknik Universitas Palembang ${ }^{1}$ \\ Alumni Prodi Teknik Elektro Universitas Palembang ${ }^{2}$
}

\begin{abstract}
ABSTRAK
Dewasa ini Indonesia sedang melaksanakan pembangunan di segala bidang. Seiring dengan laju pertumbuhan pembangunan maka dituntut adanya sarana dan prasarana yang mendukungnya seperti tersedianya tenaga listrik. Saat ini tenaga listrik merupakan kebutuhan yang utama, baik untuk kehidupan sehari-hari maupun untuk kebutuhan industri. Penyediaan tenaga listrik yang stabil dan kontinyu merupakan syarat mutlak yang harus dipenuhi dalam memenuhi kebutuhan tenaga listrik. diperlukan sebuah sistem distribusi yang mampu menyalurkan listrik dari sumber pembangkit menuju ke sasaran dengan mudah, cepat dan efisien. Salah satu instrument yang selama ini digunakan dalam sistem distribusi tersebut adalah transformator.Transformator merupakan salah satu bagian yang paling penting dalam suatu sistem tenaga listrik yang berfungsi untuk mengkonversikan tegangan dari satu tingkat ketingkat yang lainnya melalui gandengan magnetik berdasarkan prinsip elektromagnetik tanpa merubah frekuensi.Gardu induk Distribusi PT.SAMTAN-PERTA GAS mempunyai dua buah transformator, salah satunya transformator yang sampai saad ini masih dioperasikan secara terusmenerus, transformator tersebut perlu penelitian ulang dengan cara menganalisa perhitungan tentang efesiensi transformator, rugi-rugi transformator, yang disesuaikan dengan SPLN tahun 1997.
\end{abstract}

Kata Kunci : Transformator,Rugi-rugi dan Efisiensi Transformator.

\section{PENDAHULUAN}

\section{A. Latar Belakang}

Dewasa ini Indonesia sedang melaksanakan pembangunan di segala bidang. Seiring dengan laju pertumbuhan pembangunan maka dituntut adanya sarana dan prasarana yang mendukungnya seperti tersedianya tenaga listrik. Saat ini tenaga listrik merupakan kebutuhan yang utama, baik untuk kehidupan sehari-hari maupun untuk kebutuhan industri. Penyediaan tenaga listrik yang stabil dan kontinyu merupakan syarat mutlak yang harus dipenuhi dalam memenuhi kebutuhan tenaga listrik. Dalam memenuhi kebutuhan tenaga listrik tersebut, diperlukan sebuah sistem distribusi yang mampu menyalurkan listrik dari sumber pembangkit menuju ke sasaran dengan mudah, cepat dan efisien. Salah satu instrument yang selama ini digunakan dalam sistem distribusi tersebut adalah transformator.

Transformator merupakan salah satu bagian yang paling penting dalam suatu sistem tenaga listrik yang berfungsi untuk mengkonversikan tegangan dari satu tingkat ketingkat yang lainnya melalui gandengan magnetik berdasarkan prinsip elektromagnetik tanpa merubah frekuensi.

Gardu induk Distribusi PT.PERTA-SAMTAN GAS mempunyai duah buah transformator, salah satunya transformator yang masih beroperasi secara terus-menerus, transformator tersebut perlu penelitian ulang dengan cara menganalisa perhitungan tentang efesiensi transformator, rugi-rugi transformator, yang disesuaikan dengan SPLN tahun 1997.

Analisa Perhitungan Efesiensi Dan Rugi-Rugi Pada Transformator Distribusi Kilang Fraksinasi PT. Perta-Samtan Gas 


\section{B. Perumusan Masalah}

PT.SAMTAN-PERTA GAS mempunyai gardu induk transformator yang dirakit pada tahun 1997, peneliti akan tinjau dari segi efesiensi transformator, rugi-rugi transformator, yang disesuaikan dengan SPLN tahun 1997.

\section{Tujuan Penelitian}

Adapun tujuan penelitian ini adalah mengetahui besarnya efesiensi transformator, rugi-rugi transformator di gardu induk Distribusi PT.SAMTAN-PERTA GAS. .

\section{Manfaat Penelitian}

Penelitian ini diharapkan bermanfaat untuk :

1. Mahasiswa Teknik Elektro yang ingin memperdalam pengetahuan tentang transformator.

2. Hasil perhitungan, sebagai bahan masukan untuk PT.SAMTAN-PERTA GAS Gardu Induk Distribusi Transformator.

\section{E. Pembatasan Masalah}

Untuk mendapatkan hasil pembahasan yang maksimal, maka peneliti perlu membatasi masalah yang akan di bahas. Penelitian ini adalah :

- Membahas efesiensi dan rugi-rugi pada transformator yang ada pada gardu induk Distribusi Transformator PT.SAMTAN-PERTA GAS.

\section{F. Metodo Penelitian}

Untuk dapat menyelesaikan penelitian ini maka penelii menerapkan beberapa metode studi, yaitu :

1. Studi literatur, dengan membaca teori-teori yang berkaitan dengan topik penelitian ini, baik berupa buku-buku referensi, maupun dari internet.

2. Studi obserpasi, dengan melaksanakan wawan cara langsung dengan.para steak holder dan para pemangku kebijakan untuk mendapatkan data yang dibutuhkan, agar diolah dijadikan bahan sesuai object penelitian yang akan dilaksanakan.

3. Survey dilapangan untuk mengetahui tempat object penelitian sesuai yang akan direncanakan pada saat melaksanakan penelitian.

4. Data yang didapat baik dari literatur maupun data yang diperoleh dari lapangan tempat object penelitian akan diolah dan di Analisis menjadi tujuan ahir dari penelitian ini sehingga hasilnya akan di Publikasikan sesuai dengan yang diharapkan.

\section{TINJAUAN PUSTAKA}

\section{Transformator}

Transformator adalah peralatan statis yang bekerja berdasarkan prinsip induksi elektromagnet, mengkonversikan tegangan dari suatu tingkat yang lainnya melalui gandengan magnetik berdasarkan prinsip elektromagnetik dengan tanpa merubah frekuensi.

Pada umumnya transformator terdiri atas sebuah inti yang terbuat dari besi berlapis, dan dua buah kumparan yaitu kumparan primer dan kumparan sekunder. Rasio perubahan tegangan akan tergantung dari rasio jumlah lilitan pada kumparan itu. Biasanya kumparan terbuat dari kawat tembaga yang dililitkan pada kaki inti transformator.

Transformator digunakan secara luas baik dalam bidang tenaga listrik maupun elektronika. Penggunaan transformator dalam sistem tenaga memungkinkan terpilihnya tegangan yang sesuai dan ekonomis untuk tiap-tiap keperluan misalnya, kebutuhan akan tegangan tinggi dalam pengiriman daya jarak jauh.

Penggunaan transformator yang sangat sederhana dan handal merupakan salah satu alasan penting dalam pemakaiannya pada penyaluran tenaga listrik arus bolak-balik, karena arus bolak-balik sangat banyak dipergunakan untuk pembangkitan dan penyaluran tenaga listrik. Pada penyaluran tenaga listrik arus bolak-balik terjadi kerugian energi sebesar $\mathrm{I}^{2}$.R watt. Kerugian ini akan banyak berkurang apabila tegangan dinaikkan setinggi mungkin. Dengan demikian maka saluran-saluran

Analisa Perhitungan Efesiensi Dan Rugi-Rugi Pada Transformator Distribusi Kilang Fraksinasi PT. Perta-Samtan Gas 
transmisi tenaga listrik senantiasa mempergunakan tegangan yang tinggi.

\section{Keadaan Transformator Tanpa Beban}

Bila kumparan primer suatu transformator dihubungkan dengan sumber tegangan $V_{1}$ yang sinusoidal, akan mengalirkan arus primer $\mathrm{I}_{0}$ yang juga sinusoidal dan dengan menggangap belitan $\mathrm{N}_{1}$ reaktif murni. Arus primer $\mathrm{I}_{0}$ menimbulkan fluks yang sefasa dan juga berbentuk sinusoidal.

$\frac{E_{s}}{E_{p}}=\frac{V_{s}}{V_{p}}=\frac{N_{s}}{N_{p}}=\alpha$

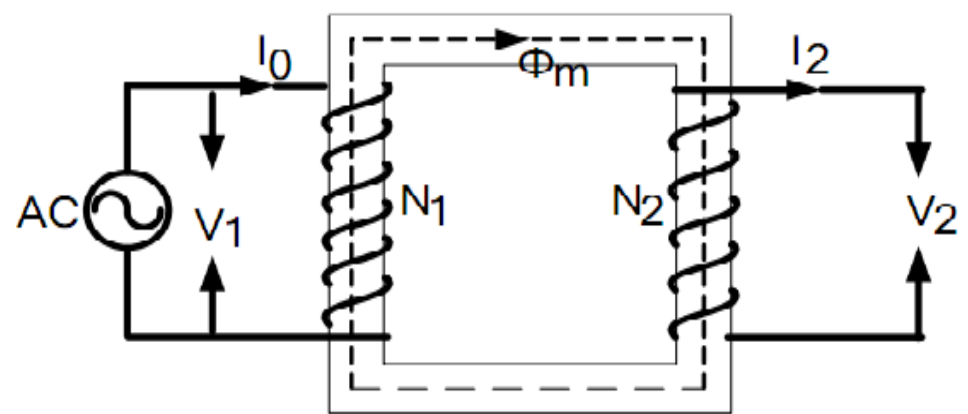

\section{Gambar 2.5 Rangkaian Sederhana Transformator Tanpa Beban}

Untuk analisa perhitungan arus beban nol, Dengan besar arus nominal sisi sekunder 289 A, maka besar presentasi arus beban nol $\left(\% \mathrm{I}_{0}\right)$ :

$\% \mathrm{I}_{0}=\frac{I_{0}(A V R)}{I_{\text {NOMINAL }}} \mathrm{X} 100 \%$

Dimana:

$I_{0}(A V R)=$ arus beban nol

$\mathrm{I}_{\text {NOMINAL }}=$ arus pada sisi sekunder

\section{Keadaan transformator berbeban}

Apabila kumparan sekunder dihubungkan dengan beban $Z_{1}, I_{2}$ mengalir pada kumparan sekunder dimana $\mathrm{I}_{2}=\mathrm{V}_{2} / \mathrm{Z}_{\mathrm{L}}$ dengan $\mathrm{q}_{2}=$ faktor kerja beban.

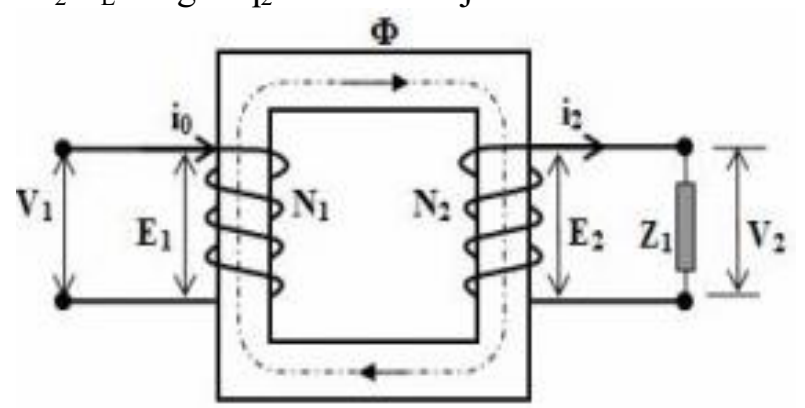

Gambar 2.6 Transformator dalam keadaan berbeban

Arus beban $\mathrm{I}_{2}$ ini akan menimbulkan gaya gerak magnet (ggm) $\mathrm{N}_{2} \mathrm{I}_{2}$ yang cenderung menentang fluks $(\Phi)$ bersama yang telah ada akibat arus pemagnetan $\mathrm{I}_{\mathrm{M}}$. Agar fluks bersama itu tidak berubah nilainya, pada kumparan primer harus mengalir arus $\mathrm{I}_{2}$, yang menentang fluks yang dibangkitkan oleh arus beban $\mathrm{I}_{2}$, hingga keseluruhan arus yang mengalir pada kumparan primer menjadi :

$\mathrm{I}_{1}=\mathrm{Io}+\mathrm{I}_{2}$

Atau

$\mathrm{I}_{\mathrm{s}}{ }^{\prime}=\mathrm{I}_{\mathrm{s}} \cdot \mathrm{V}_{\mathrm{s}} / \mathrm{V}_{\mathrm{p}}$

$\mathrm{I}_{\mathrm{p}}=\mathrm{I}_{0}+\mathrm{I}_{\mathrm{s}}{ }^{\prime}$

$\mathrm{I}_{0}=\mathrm{I}_{\mathrm{p}}-\mathrm{I}_{\mathrm{s}}{ }^{\prime}$

Analisa Perhitungan Efesiensi Dan Rugi-Rugi Pada Transformator Distribusi Kilang Fraksinasi PT. Perta-Samtan Gas

(Surya Darma / Hazalin Alferon) 
Dimana,

$\mathrm{I}_{\mathrm{p}}=$ arus sisi primer

$\mathrm{I}_{\mathrm{S}}=$ arus sisi sekunder

$\mathrm{V}_{\mathrm{s}}=$ tegangan sisi sekunder

$\mathrm{V}_{\mathrm{p}}=$ tegangan sisi primer

$\mathrm{I}_{0}=$ arus beban nol

\section{Rangkaian ekivalen Transformator}

Fluks yang dihasilkan oleh arus pemagnetan $I_{m}$ tidak seluruhnya merupakan Fluks Bersama $\left(\Phi_{M}\right)$, sebagian darinya hanya mencakup kumparan primer $\left(\Phi_{1}\right)$ atau mencakup kumparan sekunder $\left(\Phi_{2}\right)$ saja dalam model rangkain ekivalen yang dipakai untuk menganalisis kerja suatu transformator, adanya fluks bocor dengan $\Phi_{1}$ dengan mengalami proses transformasi dapat ditujukan sebagai reaktansi X1 dan fluks bocor $\Phi_{2}$ dengan mengalami proses transformasi dapat ditunjukan reaktansi X2 sedang rugi tahanan ditunjukan dengan $\mathrm{R} 1$ dan $\mathrm{R} 2$.

Dengan demikian model rangkaian dapat dituliskan seperti gambar 2.7 :

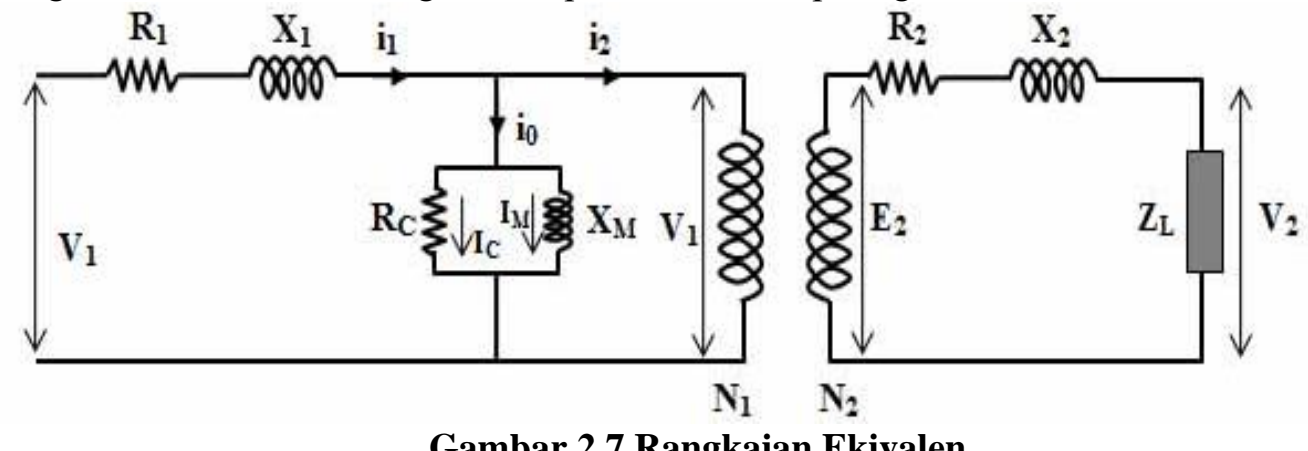

\section{METODOLOGI PENELITIAN}

Dari hasil pengumpulan data yang didapat baik dari studi literatur maupun dari data yang ada pada name flate Transformator dilapangan maupun dari steak holder yang terkait untuk kepentingan object penelitian ini sehingga dianalisa dan di olah menjadi kepentingan penelitian yang pada ahirnya akan di publikasikan.

\section{SPESIFIKASI TRANSFORMATOR}

\section{Single Line Diagram}

Diagram satu garis/ single line diagram adalah suatu diagram listrik pada gardu indukyang berisi penjelasan secara umum tentang letak, dan jenis peralatan gardu induk.Berikut adalah gambar single line diagram/ diagram satu garis, yang ada di gardu induk. 


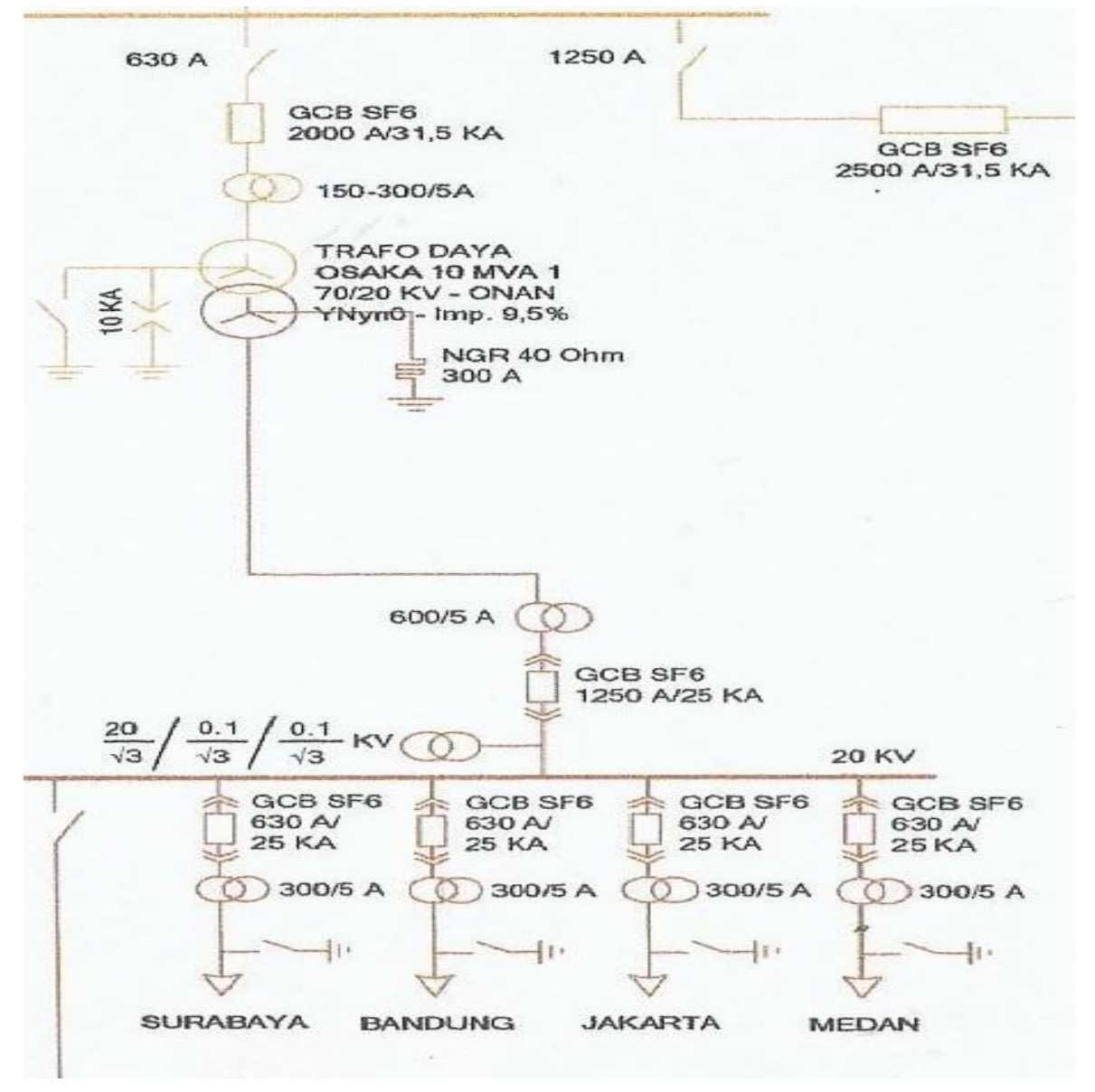

Gambar 3.1 Single Line Diagram Trafo 1 Gardu Distribusi

\section{Parameter Transformator}

Sebelum memulai analisa perhitungan ada beberapa parameter yang harus ditentukan, sehingga Hasil akhir sesuai dengan yang dikehendaki, berikut adalah data-data yang digunakan untuk menganalisa efesiensi dan rugi-rugi pada transformator.

\section{Spesifikasi Transformator tenaga}

Untuk menganalisa perhitungan efesiensi dan rugi-rugi pada transformator diperlukan data-data dari nameplate, berikut adalah spesifikasi transformator tenaga 10 MVA yang telah dibuat dengan menggunakan tabel sebagai berikut :

Tabel 3.1 Spesifikasi transformator tenaga 10 MVA

\begin{tabular}{|l|l|}
\hline Merk & OSAKA \\
\hline Serial Number & 5 A2281005 \\
\hline Year of Manufactur & 1979 \\
\hline Standard & JEC $168 ; 1966$ \\
\hline Rates Power & $10 \mathrm{MVA}$ \\
\hline Cooling & ONAN \\
\hline
\end{tabular}

Analisa Perhitungan Efesiensi Dan Rugi-Rugi Pada Transformator Distribusi Kilang Fraksinasi PT. 


\begin{tabular}{|l|l|}
\hline Frekuensi & $50 \mathrm{~Hz}$ \\
\hline Phasa & 3 \\
\hline Conection symbol & $\mathrm{Yy0}(\mathrm{Yd} 1)$ \\
\hline
\end{tabular}

Sumber data Nameplate Transformator

Tabel 3.2 Spesifikasi Data Nameplate Transformator 10 MVA

\begin{tabular}{|l|c|c|}
\hline \multicolumn{1}{|c|}{ Parameter } & Nilai & Keterangan \\
\hline Rated voltage primer & 70.000 & Volt \\
\hline Rated voltage sekunder & 20.000 & Volt \\
\hline Rated curent primer & 82,6 & Ampere \\
\hline Rated curent sekunder & 289 & Ampere \\
\hline Insulation level primer & 60 & Class \\
\hline Insulation level sekunder & 20 & Class \\
\hline Stabilizing wind & 6 & Class \\
\hline Total oil quant & 7800 & Liter \\
\hline Oil quant in main tank & 7650 & Liter \\
\hline Oil quant in tap changer & 150 & Liter \\
\hline Total wt & 28400 & $\mathrm{Kg}$ \\
\hline Lifting wt & 13700 & $\mathrm{Kg}$ \\
\hline Impedansi voltage & $\left(75^{\circ} \mathrm{c}\right) / 9,5$ & $\%$ \\
\hline
\end{tabular}

Sumber data Nameplate Transformator

\section{Data Logsheet}

Data-data pembebanan harian yang terbaca/terukur di logsheet gardu induk talang ratu yang dicatat setiap jamnya yang meliputi primer dan sekunder. yang bisa dilihat pada tabel dibawah ini :

Tabel 3.3 Pembebanan harian pada trafo 1 gardu induk Distribusi

\begin{tabular}{|c|c|c|c|c|}
\hline \multirow{2}{*}{ JAM } & \multicolumn{2}{|c|}{ PRIMER } & \multicolumn{2}{c|}{ SEKUNDER } \\
\cline { 2 - 5 } & TEGANGAN (V) & ARUS (I) & TEGANGAN (V) & ARUS (I) \\
\hline 01.00 & 65 & 18 & 20,6 & 56 \\
\hline 02.00 & 65 & 18 & 20,6 & 56 \\
\hline 03.00 & 65,6 & 18 & 20,6 & 54 \\
\hline 04.00 & 65,6 & 18 & 20,6 & 54 \\
\hline 05.00 & 65 & 22 & 20,6 & 66 \\
\hline 06.00 & 64,8 & 22 & 20,6 & 66 \\
\hline 07.00 & 64,8 & 22 & 20,6 & 67 \\
\hline 08.00 & 64,8 & 22 & 20,6 & 67 \\
\hline 09.00 & 65,6 & 26 & 20,4 & 82 \\
\hline 10.00 & 64,7 & 55 & 20,2 & 172 \\
\hline 11.00 & 64,5 & 66 & 19,9 & 202 \\
\hline 12.00 & 64,13 & 68 & 20 & 205 \\
\hline 13.00 & 64,2 & 66 & 20 & 205 \\
\hline 14.00 & 64,13 & 68 & 20 & 205 \\
\hline 15.00 & 64,13 & 68 & 20 & 202 \\
\hline 16.00 & 64,16 & 66 & 20,1 & \\
\hline \hline
\end{tabular}

Analisa Perhitungan Efesiensi Dan Rugi-Rugi Pada Transformator Distribusi Kilang Fraksinasi PT. 


\begin{tabular}{|l|l|l|l|l|}
\hline 17.00 & 64,13 & 68 & 20 & 205 \\
\hline 18.00 & 64,13 & 68 & 20 & 205 \\
\hline 18.30 & 64,13 & 68 & 20 & 205 \\
\hline 19.00 & 64,13 & 68 & 20 & 204 \\
\hline 19.30 & 64,13 & 68 & 20 & 205 \\
\hline 20.00 & 64,13 & 68 & 20 & 205 \\
\hline 20.30 & 64,13 & 68 & 20 & 205 \\
\hline 21.00 & 64,7 & 55 & 20,2 & 172 \\
\hline 22.00 & 64,7 & 55 & 20,2 & 172 \\
\hline 23.00 & 64,8 & 22 & 20,6 & 76 \\
\hline 24.00 & 64,8 & 22 & 20,6 & 66 \\
\hline
\end{tabular}

Sumber data dari hasil pengamatan bebean harian dilapangan

Nilai perhitungan yang dipakai adalah arus beban tertinggi dan terendah yang telah diwarnai. Untuk menganalisa perhitungan pada transformator, maka dalam perhitungannya diperlukan data-data yang didapat/terukur pada logsheet. Dibawah ini adalah data-data yang terukur/terbaca di logsheet gardu induk Distribusi yang dibuat dalam bentuk tabel :

Tabel 3.4 Data-data logsheet

\begin{tabular}{|c|c|}
\hline Parameter & Nilai \\
\hline Faktor daya $(\operatorname{Cos} \theta)$ & 0,92 \\
\hline $\begin{array}{c}\text { Tegangan pada titik nol } \\
\left(\mathrm{V}_{0}\right)\end{array}$ & 230 \\
\hline
\end{tabular}

\section{Standar Perusahaan Listrik Negara}

SPLN adalah standar perusahaan PT PLN ( Persero ) yang ditetapkan Direksi bersifat wajib. Dapat berupa peraturan, pedoman, instruksi, cara pengujian dan spesifikasi teknik. Sejak tahun 1976 sudah lebih dari 264 buah standar berhasil dirampungkan 61 standar bidang pembangkitan, 71 standar bidang transmisi, 99 standar bidang distribusi dan 33 standar bidang umum.Berikut adalah tabel pedoman, peraturan, intruksi, transformator 3 phasa yang bersifat wajib :

Tabel 3.5 Standar Perusahaan Listrik Negara

\begin{tabular}{|c|c|c|c|c|c|}
\hline $\begin{array}{c}\text { Tegangan } \\
\begin{array}{c}\text { Primer } \\
(\mathrm{kV})\end{array}\end{array}$ & $\begin{array}{c}\text { Daya } \\
\text { Pengenal } \\
(\text { MVA })\end{array}$ & $\begin{array}{c}\text { Rugi } \\
\text { Beban Nol } \\
(\mathrm{kW})\end{array}$ & $\begin{array}{c}\text { Arus } \\
\text { Beban Nol } \\
(\%)\end{array}$ & $\begin{array}{c}\text { Rugi } \\
\text { Beban Penuh } \\
(\mathrm{kW})\end{array}$ & Efisiensi \\
\hline \multirow{6}{*}{$66 / 20 \mathrm{kV}$} & 5 & 6 & 1,5 & 32 & 99,25 \\
\cline { 2 - 6 } & 6,3 & 6,7 & 1,3 & 36 & 99,33 \\
\cline { 2 - 6 } & 10 & 7,5 & 1,1 & 40 & 99,53 \\
\cline { 2 - 6 } & 16 & 9,6 & 0,9 & 63 & 99,55 \\
\cline { 2 - 6 } & 20 & 12 & 0,8 & 775 & 99,57 \\
\hline $150 / 20 \mathrm{kV}$ & 10 & 8,5 & 1 & 100 & 99,6 \\
\hline
\end{tabular}

Analisa Perhitungan Efesiensi Dan Rugi-Rugi Pada Transformator Distribusi Kilang Fraksinasi PT. 


\begin{tabular}{|c|c|c|c|c|c|} 
& 20 & 14 & 0,8 & 75 & 99,56 \\
\cline { 2 - 6 } & 30 & 23 & 0,8 & 103 & 99,58 \\
\cline { 2 - 6 } & 60 & 38 & 0,95 & 220 & 99,57 \\
\hline \multirow{3}{*}{$150 / 66 \mathrm{kV}$} & 30 & 25 & 0,9 & 107 & 99,56 \\
\cline { 2 - 6 } & 60 & 39 & 0,9 & 225 & 99,56 \\
\cline { 2 - 6 } & 100 & 42 & 0,9 & 330 & 99,63 \\
\hline $500 / 150 \mathrm{kV}$ & 500 & 98 & 0,45 & 349 & 99,91 \\
\hline
\end{tabular}

Dibawah ini adalah tabel konstanta untuk berbagai jenis transformator yang telah ditetapkan oleh standar perusahaan listrik negara (SPLN) yang diperlukan dalam menganalisa perhitungan efesiensi dan rugi-rugi pada transformator, konstanta yang dipakai adalah transformator tiga phasa jenis inti yang dapat dilihat pada tabel dibawah ini yang telah diwarnai :

Tabel 3.6 Konstanta sisi sekunder berbagai jenis transformator

\begin{tabular}{|l|l|c|}
\hline No. & \multicolumn{1}{|c|}{ Jenis } & Konstanta (K) \\
\hline 1 & Trafo 1 fasa jenis cangkang & $1-1,2$ \\
\hline 2 & Trafo 1 fasa jenis inti & $0.75-0.85$ \\
\hline 3 & Trafo 3 fasa jenis cangkang & 1,3 \\
\hline 4 & Trafo 3 fasa jenis inti & 0,51 \\
\hline
\end{tabular}

Sumber data Nameplate standart Transformator

\section{ANALISA HASIL DAN PEMBAHASAN}

\section{Perhitungan Arus Beban nol}

Dengan besar arus nominal sisi sekunder 289 A yang didapat dari data nameplate, $\mathrm{I}_{0}$ (arus nol) yang belum diketahui, maka dapat ditentukan dengan menggunakan persamaan (2.4) sebagai berikut :

$\mathrm{I}_{\mathrm{s}}{ }^{\prime}=\mathrm{I}_{\mathrm{s}} \cdot\left(\frac{V_{s}}{V_{p}}\right)$

$\mathrm{I}_{\mathrm{s}}{ }^{\prime}=$ Is $.(\alpha)=289.0,28$

$\mathrm{I}_{\mathrm{s}}{ }^{\prime}=80,92$

$\mathrm{I}_{\mathrm{p}}=\mathrm{I}_{0}+\mathrm{I}_{\mathrm{s}}{ }^{\prime}$

$\mathrm{I}_{0}=\mathrm{I}_{\mathrm{p}}-\mathrm{I}_{\mathrm{s}}{ }^{\prime}=82,6-80,92$

$\mathrm{I}_{0}=1,68 \mathrm{~A}$

Dengan hasil $\mathrm{I}_{0}$ yang diketahui adalah $(1,68)$ maka dapat ditentukan arus beban nol dari persamaan (2.2) adalah sebagai berikut :

$\% \mathrm{I}_{0}=\frac{I_{0}(A V R)}{I_{\text {NOMINAL }}} \times 100 \%=\frac{1,68}{289} \times 100 \%=0,58 \%$

\section{Data Terukur}

Berikut adalah perhitungan yang menggunakan data yang terbaca/terukur di logsheet, dari arus beban $\left(\mathrm{I}_{\mathrm{s}}\right)$ tertinggi.

$$
\begin{aligned}
& \mathrm{I}_{\mathrm{s}}{ }^{\prime}=\mathrm{I}_{\mathrm{s}} \cdot\left(\frac{V_{s}}{V_{p}}\right) \\
& \mathrm{I}_{\mathrm{s}}{ }^{\prime}=\mathrm{Is} .(\alpha)=205 \cdot 0,28 \\
& \mathrm{I}_{\mathrm{s}}{ }^{\prime}=57,4 \\
& \mathrm{I}_{\mathrm{p}}=\mathrm{I}_{0}+\mathrm{I}_{\mathrm{s}}{ }^{\prime}
\end{aligned}
$$

Analisa Perhitungan Efesiensi Dan Rugi-Rugi Pada Transformator Distribusi Kilang Fraksinasi PT. 
$\mathrm{I}_{0}=\mathrm{I}_{\mathrm{p}}-\mathrm{I}_{\mathrm{s}}{ }^{\prime}=68-57,4$

$\mathrm{I}_{0}=10,6 \mathrm{~A}$

Maka,

$\% \mathrm{I}_{0}=\frac{I_{0}(A V R)}{I_{\text {NOMINAL }}} \times 100 \%=\frac{10,6}{205} \times 100 \%=5,1 \%$

Dibawah ini adalah perhitungan yang menggunakan data yang terbaca/terukur di logsheet, dari arus beban $\left(\mathrm{I}_{\mathrm{s}}\right)$ terendah.

$\mathrm{I}_{\mathrm{s}}{ }^{\prime}=\mathrm{I}_{\mathrm{s}} \cdot\left(\frac{V_{s}}{V_{p}}\right)$

$\mathrm{I}_{\mathrm{s}}{ }^{\prime}=\mathrm{Is} .(\alpha)=54.0,28$

$\mathrm{I}_{\mathrm{s}}{ }^{\prime}=15,12$

$\mathrm{I}_{\mathrm{p}}=\mathrm{I}_{0}+\mathrm{I}_{\mathrm{s}}{ }^{\prime}$

$\mathrm{I}_{0}=\mathrm{I}_{\mathrm{p}}-\mathrm{I}_{\mathrm{s}}{ }^{\prime} \quad=18-15,12$

$\mathrm{I}_{0}=2,88 \mathrm{~A}$

Maka,

$\% \mathrm{I}_{0}=\frac{I_{0}(A V R)}{I_{\text {NOMINAL }}} \times 100 \%=\frac{2,88}{54} \times 100 \%=5,3 \%$

\section{Analisa Hasil Perhitungan Arus Beban nol}

Menurut SPLN TA 1997 Persentase arus beban nol $\left(\% \mathrm{I}_{0}\right)$ maksimum untuk transformator 10 MVA adalah $1,1 \%$. persentase arus beban nol dari beban tertinggi $(5,1 \%)$ dan persentase arus beban nol dari beban terendah adalah $(5,3 \%)$, dilihat dari perhitungan arus beban nol melebihi standar yang ditetapkan, maka arus beban nolnya dinyatakan kurang baik.

\section{Rugi-rugi Transformator}

Pada transformator tidak terdapat bagian yang bergerak, sehingga tidak ada rugi akibat gesekan atau rugi pada celah, rugi yang terjadi pada transformator meliputi :

\section{Rugi Beban Nol}

Besarnya rugi-rugi beban nol transformator, dapat ditentukan dengan persamaan (2.5), yang menggunakan data nameplate.

$$
\sum \text { rugi }- \text { rugi }=V_{0} . I_{0} \cdot \sqrt{3}=230.1,68.1,73=668,472 \mathrm{VA}=\frac{668,472 \times \cos \theta}{1000}=0,61 \mathrm{~kW}
$$

\section{Data Terukur}

Berikut adalah perhitungan yang menggunakan data yang terbaca/terukur di logsheet, dari arus beban $\left(\mathrm{I}_{\mathrm{s}}\right)$ tertinggi.

$$
\begin{aligned}
\text { Srugi }- \text { rugi } & =V_{0} \cdot I_{0} \cdot \sqrt{3}=230.10,6.1,73 \\
& =4217,74 \mathrm{VA} \\
& =\frac{4217,74 x \cos \theta}{1000} \\
& =3,88 \mathrm{~kW}
\end{aligned}
$$

Dibawah ini adalah perhitungan yang menggunakan data yang terbaca/terukur di logsheet, dari arus beban $\left(\mathrm{I}_{\mathrm{s}}\right)$ terendah.

$$
\text { Srugi }- \text { rugi }=V_{0} . I_{0} \cdot \sqrt{3}=230.2,88.1,73=1145,952 \mathrm{VA}=\frac{1145,952 x \cos \theta}{1000}=1,05 \mathrm{~kW}
$$

\section{Analisa Hasil Perhitungan Rugi Beban Nol}

Menurut dari perhitungan diatas rugi beban nol dari data yang terukur di logsheet untuk beban tertinggi didapat $(3,88 \mathrm{KW})$ beban terendah didapat $(1,05 \mathrm{KW})$, menurut SPLN TA 1997 rugi beban nol maksimum untuk transformator 10 MVA adalah $(7,5 \mathrm{KW})$, melihat dari hasil perhitungannya maka rugi-rugi beban nol pada transformator tersebut masih memenuhi standar, dan dinyatakan masih baik.

Analisa Perhitungan Efesiensi Dan Rugi-Rugi Pada Transformator Distribusi Kilang Fraksinasi PT. 


\section{Rugi Beban penuh}

Besarnya rugi-rugi transformator beban penuh dapat ditentukan dengan menggunakan persamaan (2.6), Data beban dari nameplate.

$\mathrm{P}_{\mathrm{cu}}=\mathrm{I}_{\mathrm{s}}^{2} \cdot \mathrm{R}_{\mathrm{es}}=289^{2} \times 0,07=5846,47$ Watt

$\mathrm{P}_{\mathrm{i}}=\mathrm{P}_{\mathrm{h}}+\mathrm{P}_{\mathrm{e}}$

$\mathrm{P}_{\mathrm{h}}=\mathrm{K}_{\mathrm{h}}$. f . $\mathrm{B}^{1.6}{ }_{\text {maks }}=0,51 \times 50 \times 0,34=8,67$

$\mathrm{P}_{\mathrm{e}}=\mathrm{K}_{\mathrm{e}}^{2} \cdot \mathrm{f}^{2} \cdot \mathrm{B}_{\text {maks }}^{2}=0,51^{2} \times 50^{2} \times 0,26=169$

$\mathrm{Pi}=8,67+169=177,67$ Watt

Maka,

$\sum$ rugi $=\mathrm{p}_{\mathrm{cu}}+\mathrm{p}_{\mathrm{i}}=5846,47+177,67=6024,14 \mathrm{Watt}=6,02 \mathrm{~kW}$

\section{Data Terukur}

Berikut adalah perhitungan yang menggunakan data yang terbaca/terukur di logsheet, dari arus beban $\left(\mathrm{I}_{\mathrm{S}}\right)$ tertinggi.

$\mathrm{P}_{\mathrm{cu}}=\mathrm{I}_{\mathrm{s}}^{2} \cdot \mathrm{R}_{\mathrm{es}}=205^{2} \times 0,08=3362 \mathrm{Watt}$

$\mathrm{P}_{\mathrm{i}}=\mathrm{P}_{\mathrm{h}}+\mathrm{P}_{\mathrm{e}}$

$\mathrm{P}_{\mathrm{h}}=\mathrm{K}_{\mathrm{h}} \cdot \mathrm{f} . \mathrm{B}^{1.6}{ }_{\text {maks }}=0,51 \times 50 \times 0,34=8,67$

$\mathrm{P}_{\mathrm{e}}=\mathrm{K}_{\mathrm{e}}{ }^{2} \cdot \mathrm{f}^{2} \cdot \mathrm{B}_{\mathrm{maks}}{ }^{2}=0,51^{2} \times 50^{2} \times 0,26=169$

$\mathrm{Pi}=8,67+169=177,67$ Watt

Maka,

$\sum$ rugi $=\mathrm{p}_{\mathrm{cu}}+\mathrm{p}_{\mathrm{i}}=3362+177,67=3539,67 \mathrm{Watt}=3,53 \mathrm{~kW}$

Dibawah ini adalah perhitungan yang menggunakan data yang terbaca/terukur di logsheet, dari arus beban $\left(\mathrm{I}_{\mathrm{S}}\right)$ terendah.

$\mathrm{P}_{\mathrm{cu}}=\mathrm{I}_{\mathrm{s}}^{2} \cdot \mathrm{R}_{\mathrm{es}}=54^{2} \times 0,31=903,96 \mathrm{Watt}$

$P_{i}=P_{h}+P_{e}$

$\mathrm{P}_{\mathrm{h}}=\mathrm{K}_{\mathrm{h}} \cdot \mathrm{f} \cdot \mathrm{B}^{1.6}{ }_{\text {maks }}=0,51 \times 50 \times 0,34=8,67$

$\mathrm{P}_{\mathrm{e}}=\mathrm{K}_{\mathrm{e}}{ }^{2} \cdot \mathrm{f}^{2} \cdot \mathrm{B}_{\text {maks }}{ }^{2}=0,51^{2} \times 50^{2} \times 0,26=169$

$\mathrm{Pi}=8,67+169=177,67$ Watt

Maka,

$\sum$ rugi $=\mathrm{p}_{\mathrm{cu}}+\mathrm{p}_{\mathrm{i}}=903,96+177,67=1081,63 \mathrm{Watt}=1,08 \mathrm{~kW}$

\section{Analisa Perhitungan Rugi Beban Penuh}

Menurut dari perhitungan diatas rugi beban penuh dari beban tertinggi didapat (3,53 KW) dan dari beban terendah didapat (1,08 KW) menurut SPLN TA 1997 rugi beban penuh maksimum untuk transformator 10 MVA adalah $(40 \mathrm{KW})$, melihat dari hasil perhitungannya maka rugi-rugi beban penuh pada transformator tersebut masih memenuhi standar, dan dinyatakan masih baik.

\section{Perhitungan Efesiensi Transformator}

Efisiensi transformator didefinisikan sebagai perbandingan antara daya listrik keluaran dengan daya listrik yang masuk pada transformator. Pada transformator ideal efisiensinya $100 \%$, tetapi pada kenyataannya efisiensi tranformator selalu kurang dari $100 \%$.

Hal ini karena sebagian energi terbuang menjadi panas atau energi bunyi. Berikut adalah data perhitungan yang menggunakan data name plate dengan menggunakan persamaan (2.11) :

$\mathrm{P}_{\mathrm{p}}=\mathrm{V}_{\mathrm{p}} \cdot \mathrm{I}_{\mathrm{p}} \cdot \sqrt{3} \cdot \operatorname{Cos} \theta=70000 \times 82,6 \times 1,73 \times 0,92=9202631,2$

$\mathrm{P}_{\mathrm{s}}=\mathrm{V}_{\mathrm{s}} \cdot \mathrm{I}_{\mathrm{s}} \cdot \sqrt{3} \cdot \operatorname{Cos} \theta=20000 \times 289 \times 1,73 \times 0,92=9199448=\frac{P_{\text {out }}}{P_{\text {in }}} \times 100 \%=\frac{9199448}{9202631,2} \times 100 \%=$ $99,96 \%$

\section{Data Terukur}

Analisa Perhitungan Efesiensi Dan Rugi-Rugi Pada Transformator Distribusi Kilang Fraksinasi PT. Perta-Samtan Gas 
Berikut adalah perhitungan yang menggunakan data yang terbaca/terukur di logsheet, dari arus beban $\left(\mathrm{I}_{\mathrm{s}}\right)$ tertinggi.

$$
\begin{aligned}
\mathrm{P}_{\mathrm{p}} & =\mathrm{V}_{\mathrm{p}} \cdot \mathrm{I}_{\mathrm{p}} \cdot \sqrt{3} \cdot \operatorname{Cos} \theta=64,13 \times 68 \times 1,73 \times 0,92=6940,71294 \mathrm{P}_{\mathrm{s}}=\mathrm{V}_{\mathrm{s}} \cdot \mathrm{I}_{\mathrm{s}} \cdot \sqrt{3} \cdot \operatorname{Cos} \theta \\
& =20 \times 205 \times 1,73 \times 0,92=6525,56 \\
\eta & =\frac{P_{\text {out }}}{P_{\text {in }}} \times 100 \%=\frac{6525,56}{6940,71294} \times 100 \%=94,01 \%
\end{aligned}
$$

Dibawah ini adalah perhitungan yang menggunakan data yang terbaca/terukur di logsheet, dari arus beban $\left(\mathrm{I}_{\mathrm{s}}\right)$ terendah.

$\mathrm{P}_{\mathrm{p}}=\mathrm{V}_{\mathrm{p}} \cdot \mathrm{I}_{\mathrm{p}} \cdot \sqrt{3} \cdot \operatorname{Cos} \theta=65,6 \times 18 \times 1,73 \times 0,92=1879,36128$

$\mathrm{P}_{\mathrm{s}}=\mathrm{V}_{\mathrm{s}} \cdot \mathrm{I}_{\mathrm{s}} \cdot \sqrt{3} \cdot \operatorname{Cos} \theta=20,6 \times 54 \times 1,73 \times 0,92=1770,49584$

$\eta=\frac{P_{\text {out }}}{P_{\text {in }}} \times 100 \%=\frac{1770,49584}{1879,36128} \times 100 \%=94,20 \%$

\section{Analisa Perhitungan Efesiensi Transformator}

Menurut SPLN TA 1997 Presentase efesiensi maksimum untuk transformator 10 MVA adalah $(99,53 \%)$. Maka dapat disimpulkan efesiensi transformator tersebut tingkat efesiensinya rendah, persentase efisiensi dari beban tertinggi $(94,01 \%)$ dan persentase efisiensi terendah adalah $(94,20 \%)$, melihat dari perhitungan diatas maka dinyatakan kurang efisien.

\section{Hasil Perhitungan}

Setelah melakukan perhitungan, maka dapat dibandingkan dengan tabel Standar Perusahaan Listrik Negara (SPLN), sebagai pedoman, peraturan yang wajib. Dapat dilihat pada tabel dibawah ini :

Tabel 4.1 Standar perusahaan listrik Negara

\begin{tabular}{|c|c|c|c|c|c|}
\hline $\begin{array}{c}\text { Tegangan } \\
\text { Primer }\end{array}$ & $\begin{array}{c}\text { Daya } \\
\text { Pengenal }\end{array}$ & $\begin{array}{c}\text { Rugi Beban } \\
\text { Nol }\end{array}$ & $\begin{array}{c}\text { Arus Beban } \\
\text { Nol }\end{array}$ & $\begin{array}{c}\text { Rugi Beban } \\
\text { Penuh }\end{array}$ & Efisiensi \\
\cline { 5 - 7 }$(\mathrm{kV})$ & $($ MVA $)$ & $(\mathrm{kW})$ & $(\%)$ & $(\mathrm{kW})$ & $(\%)$ \\
\hline \multirow{5}{*}{$66 / 20 \mathrm{kV}$} & 5 & 6 & 1,5 & 32 & 99,25 \\
\cline { 2 - 6 } & 6,3 & 6,7 & 1,3 & 36 & 99,33 \\
\cline { 2 - 7 } & 10 & 7,5 & 1,1 & 40 & 99,53 \\
\cline { 2 - 7 } & 16 & 9,6 & 0,9 & 63 & 99,55 \\
\cline { 2 - 7 } & 20 & 12 & 0,8 & 775 & 99,57 \\
\hline
\end{tabular}

Sumber data hasil Perhitungan

Berdasarkan perhitungan dari lembar-lembar sebelumnya, dan mendapatkan hasil yang dapat dilihat pada tabel hasil perhitungan, dapat dibandingkan dengan tabel Standar Perusahaan Listrik Negara, transformator yang digunakan dapat dilihat pada tabel yang berwana, apakah memenuhi syarat standarnya atau tidak, tabel hasil perhitungannya adalah sebagai berikut :

Tabel 4.2 Hasil perhitungan

\begin{tabular}{|c|c|c|c|c|c|c|c|c|}
\hline $\begin{array}{c}\text { Tegan } \\
\text { gan } \\
\text { primer }\end{array}$ & $\begin{array}{c}\text { Daya } \\
\text { pengenal }\end{array}$ & Jam & Beban & $\begin{array}{c}\text { Rugi } \\
\text { Beban } \\
\text { Nol }\end{array}$ & $\begin{array}{c}\text { Arus } \\
\text { Beban } \\
\text { Nol }\end{array}$ & $\begin{array}{c}\text { Rugi } \\
\text { Beban } \\
\text { Penuh }\end{array}$ & Efesiensi & $\begin{array}{c}\text { Efesiensi } \\
\text { SPLN }\end{array}$ \\
\hline $66 / 20$ & 10 & 01.00 & 56 & 0,84 & 4,14 & 1,11 & 98,59 & 99,53 \\
\hline
\end{tabular}

Analisa Perhitungan Efesiensi Dan Rugi-Rugi Pada Transformator Distribusi Kilang Fraksinasi PT. Perta-Samtan Gas 


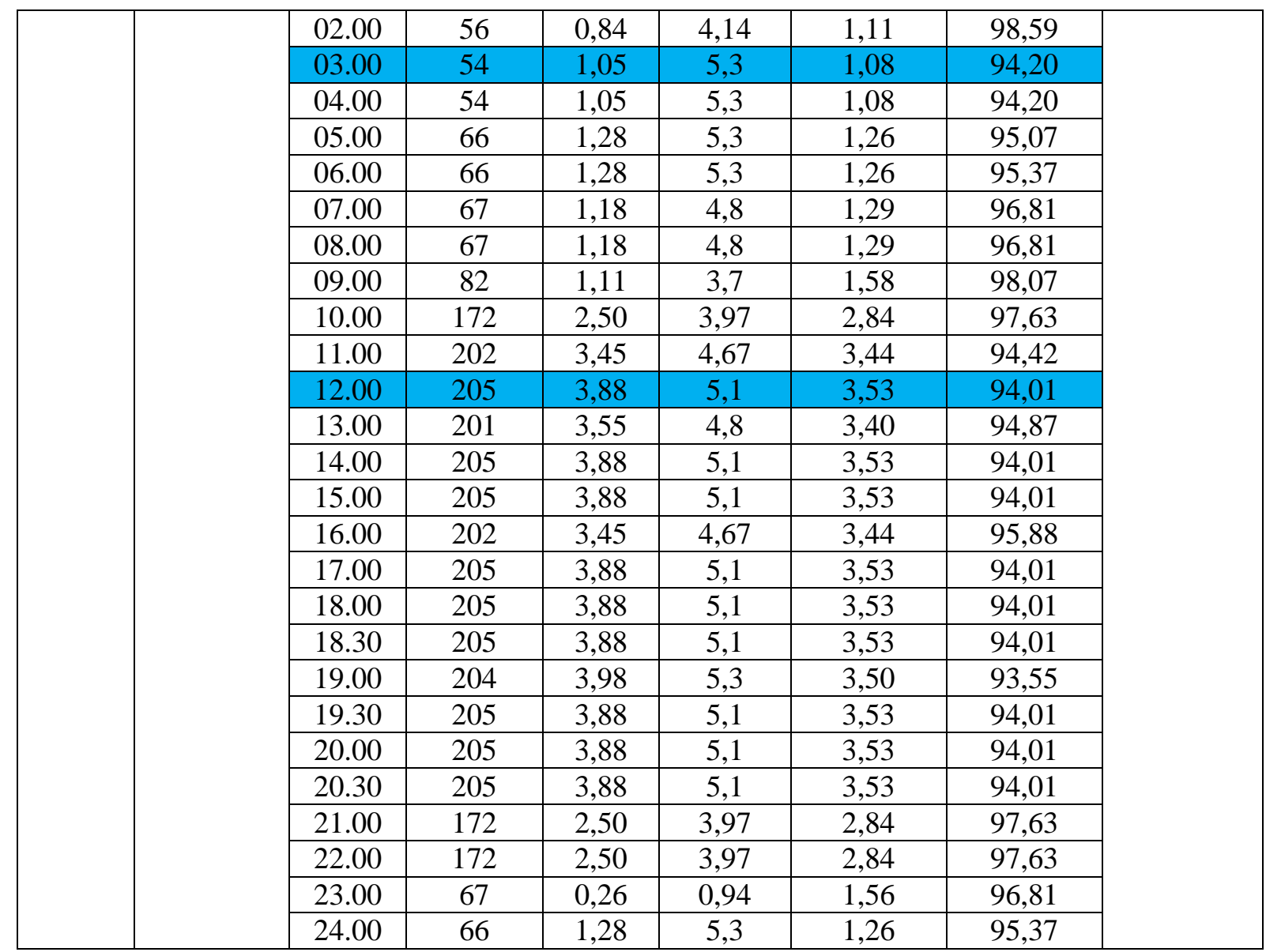

Sumber data hasil Perhitungan

\section{PENUTUP KESIMPULAN \& SARAN}

\section{A.KESIMPULAN}

Berdasarkan hasil analisa perhitungan yang dilakukan, maka dapat disimpulkan hal-hal sebagai berikut :

1. Hasil perhitungannya maka rugi-rugi beban nol pada transformator tersebut masih memenuhi standar, dan dinyatakan masih baik, rugi beban nol dari hasil perhitungan beban tertinggi didapat $(3,88 \mathrm{~kW})$ beban terendah didapat $(1,05 \mathrm{~kW})$ sedangkan standar PLN $(7,5 \mathrm{~kW})$.

2. Hasil perhitungannya maka rugi-rugi beban penuh pada transformator tersebut masih memenuhi standar, dan dinyatakan masih baik, rugi beban penuh dari hasil perhitungan beban tertinggi didapat $(3,53 \mathrm{~kW})$ beban terendah didapat $(1,08 \mathrm{~kW})$ sedangkan standar PLN (40 $\mathrm{kW})$.

3. Efesiensi transformator tersebut kurang efisien dan tidak layak untuk beroperasi, berdasarkan dari hasil perhitungan beban tertinggi didapat $(94,01 \%)$ dan hasil perhitungan beban terendah

\section{B SARAN} didapat efesiensinya (94,20\%), sedangkan efesiensi standar PLN $(99,53 \%)$.

Saran yang dapat diberikan dalam menganalisa kemampuan transformator ini adalah :

Untuk mengoperasikan transformator secara optimum, pengoperasian dan pemeliharaan harus secara khusus memperlihatkan berbagai faktor yang menyebabkan memburuknya tingkat persentase efesiensi, maka disarankan untuk menggunakan buku standar perusahaan listrik negara (SPLN) sebagai pedoman, aturan, instruksi, yang ditetapkan Direksi bersifat wajib.

\section{DAFTAR PUSTAKA}

[1] DR. A. Arismunandar, DR. Kuwara, Teknik Tenaga Listrik, Jilid 2,1993. 
[2] Ir.Muslimin Marappung, Teknik Tenaga Listrik dan Penyelesaian Soal-Soal

[3] ZUHAL. Dasar Teknik Listrik. ITB BANDUNG 1991

[4] Dr.Suyitno M. M.Pd. Pembangkit Energi Listrik

[5] Djiteng Marsudi. Operasi Sistem Tenaga Listrik

[6] SPLN TAHUN 1997. Standarisasi PT.PLN (Persero).

Analisa Perhitungan Efesiensi Dan Rugi-Rugi Pada Transformator Distribusi Kilang Fraksinasi PT. Perta-Samtan Gas

(Surya Darma / Hazalin Alferon) 